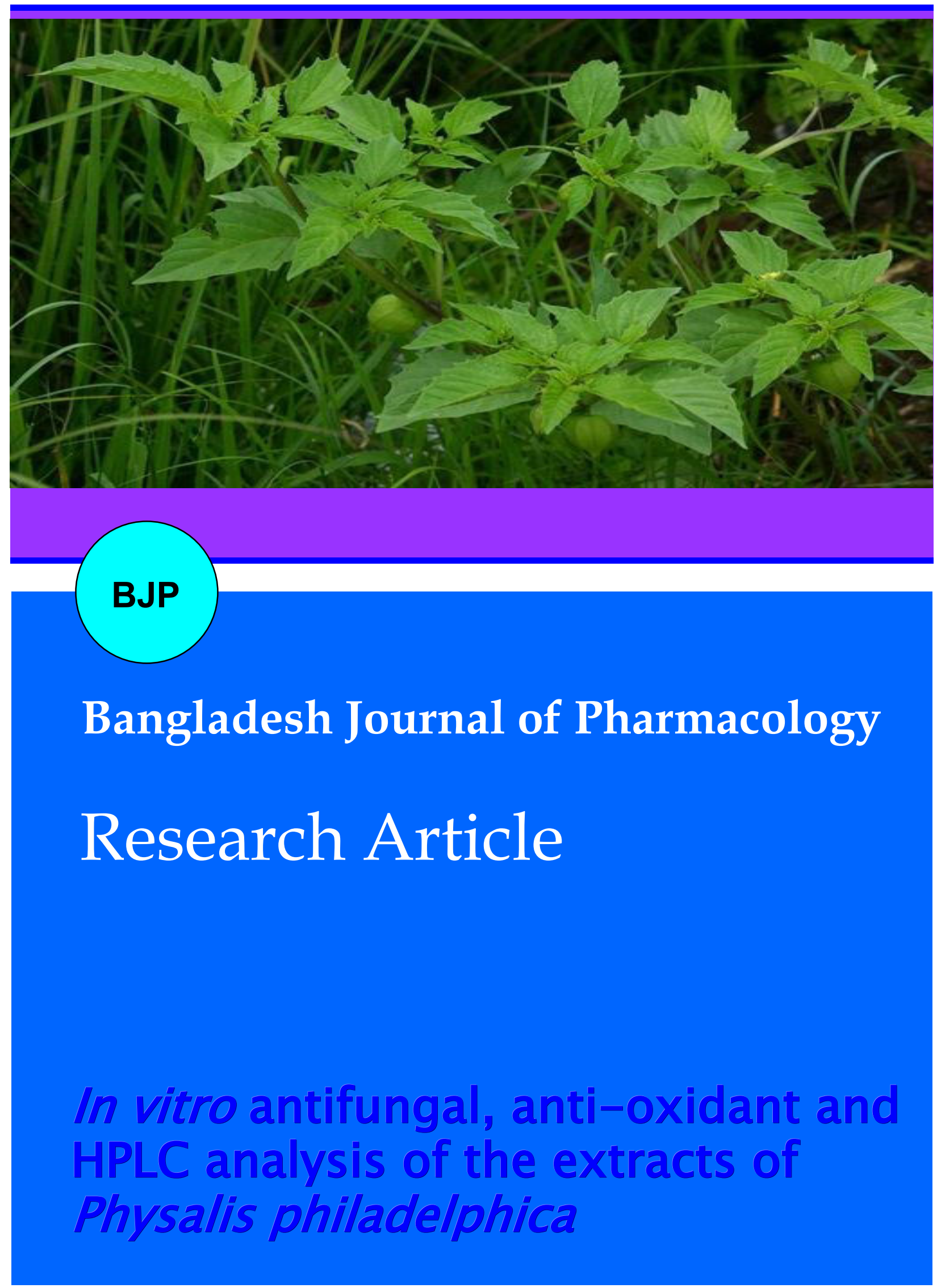




\title{
In vitro antifungal, anti-oxidant and HPLC analysis of the extracts of Physalis philadelphica
}

\author{
Wajid Khan', Jehan Bakht² and Bilal Muhammad Khan²
}

${ }^{1}$ Centre for Biotechnology and Microbiology, University of Swat, Khyber Pakhtunkhwa, Pakistan; ${ }^{2}$ Institute of Biotechnology and Genetic Engineering, The University of Agriculture, Peshawar, Pakistan.

\begin{tabular}{|c|c|}
\hline \multicolumn{2}{|l|}{ Article Info } \\
\hline Received: & 28 March 2017 \\
\hline Accepted: & 13 August 2017 \\
\hline Available Online: & 30 August 2017 \\
\hline \multicolumn{2}{|c|}{ DOI: 10.3329/bjp.v12i3.31965 } \\
\hline \multicolumn{2}{|c|}{$\begin{array}{l}\text { Cite this article: } \\
\text { Khan W, Bakht J, Khan BM. In vitro } \\
\text { antifungal, anti-oxidant and HPLC } \\
\text { analysis of the extracts of Physalis } \\
\text { philadelphica. Bangladesh J Pharmacol. } \\
\text { 2017; 12: 313-18. }\end{array}$} \\
\hline
\end{tabular}

\section{Abstract}

The different parts of Physalis philadelphica were evaluated for the antifungal, anti-oxidant and HPLC assay. The methanol extract of leaf showed inhibitory activity against Pencillium digitatum (58\% ZI), Aspergillus flavus (95\% ZI) and Rhizopus oryzae $(96 \% \mathrm{ZI})$ at a concentration of $400 \mathrm{ppm}$. Strong anti-oxidant activities were found in different parts of the plant. The effects of different extraction solvents on the anti-oxidant activity and antifungal activity of the medicinal extracts were observed. The methanol extract from the leaf, stem, fruit and water fractions from the calyx exhibited strong anti-oxidant activity of $94,89,88$ and $93 \%$ respectively. The ethyl acetate extract was found as a best solvent for the recovery of gallic acid in HPLC assay. No correlation was observed between the gallic acid and anti-oxidant capacity of the extracts.

\section{Introduction}

Fungal infection of grains is common in agriculture depending countries and causes significant loss of foodstuffs by retarding its nutritive value and make them unfit for human consumption (Devi et al., 2001; Marin et al., 1999). Contaminated cereals with fungi are the principal source of mycotoxin (Desjardins et al., 2000; Galvano et al., 2001). A large portion of the peoples in the developing countries is suffered from the health problems associated with mycotoxin contamination of grain and cereal (Majumder et al., 1997). Due to the toxic effect of synthetic fungicide, it cannot be applied directly to grains (Dukic et al., 2004). Therefore, it is the need of the time to search an alternative approach to store the grains with no toxic effect on the human and animal health.

Extracts produced from the different parts of the plants exhibit antifungal, antibacterial and insecticidal activities under lab trial as reported earlier (Khan et al., 2016; Ullah et al., 2015). Secondary metabolites of plants with pesticidal activity are one of the best alternatives to synthetic chemicals, with least toxic effect and ecofriendly (Varma and Dubey, 1999). This led to researchers to screen out the natural flora for the presence of antifungal bioactive compounds.

The anti-oxidants of the plant source have good impact on the human health and reduce the risk of diseases (Gulçin et al., 2003). The frequency of cancer and cardio -vascular diseases can effectively lower with the use of plant-derived anti-oxidants (Arabshahi and Urooj, 2007). Extraction of anti-oxidant depends on the nature of extracting solvent. Thus, preliminary screening is necessary to pinpoint the favorable solvents that finalize the optimum antifungal and radical scavenging activity for the extracts.

Now-a-days HPLC assay is widely used for the evaluation of polyphenol content in herbal extracts, due to its sensitivity, repeatability and accuracy (Granger et al., 2011; Khan and Bakht, 2016). In the present study, the different extracts were screened for the presence of gallic acid (polyphenol) using this assay for the aforesaid reasons. 
Cited literatures indicated that there were no attempts to investigate the medicinal importance of different parts of Physalis philadelphica, though its different parts are used as folk medicine. In the light of this background, the current study was designed to determine the bioactivities and HPLC of different parts of $P$. philadelphica.

\section{Materials and Methods}

\section{Collection and identification of plant materials}

Plant material of P. philadelphica, was collected from the District Shangla Khyber Pakhtun Khwa, Pakistan. The plant specimen was identified by Prof. Farukh Hussain, plant taxonomist and deposited in the herbarium of the Department of Botany University of Peshawar, Pakis$\tan$.

\section{Chemicals, media and other accessories}

Different solvents (methanol, $n$-hexane, ethyl acetate, $n$ butanol) used in this study were HPLC, gradient grade ( $\geq 99.9 \%)$. Potato dextrose agar (70139 Sigma-Aldrich), potato dextrose broth (P6685 Sigma-Aldrich), dimethyl sulfoxide (DMSO) (1211006 Sigma-Aldrich), gallic acid (91215 Sigma-Aldrich), 2,2-diphenyl-1-picrylhydrazyl (D9132 - DPPH) and fluconazole were purchased from the local supplier. The rotary evaporator (Rotavapor RR 210/R215; BUCHI Labortechnik AG) was used to evaporate solvents. HPLC spectra were recorded with prominence diode array, PDA, detector (Shimadzu SPD -M20A).

\section{Preparation of crude extracts of stem, leaf and fruit}

The clean plant material was dried in the shade. The dried material was powdered in an electric grinder. Seven hundred gram of dried powder was stirred in the extraction flask containing $3 \mathrm{~L}$ of analytical grade methanol. These extraction flasks were kept at room temperature and shaken twice daily for 6 days. Whatman filter paper No. 1 was used to filter the solution. The solid residue was then treated three times with $1,500 \mathrm{~mL}$ of fresh methanol. The filtrate was dried in a rotary evaporator to obtain the crude methanol extract. The extract was desiccated in a desiccator at $40^{\circ} \mathrm{C}$ (Bakht et al., 2011 a, d).

\section{Fractionation procedure (Figure 1)}

The crude methanol extract was separated into two parts. One part (10 g) was stored in a glass vial to be tested as crude methanolic extracts for antifungal and anti-oxidant activities while the other part (92 g) was dissolved in $300 \mathrm{~mL}$ of water, transferred to a separating funnel to obtain the fractions of the crude extract. An equal volume of analytical grade $n$-hexane was poured into the separation funnel, gently upset it, and then keeps it undisturbed for a moment to separate the two layers. The upper layer of $n$-hexane fraction of the crude extract was collected in the flask and the lower aqueous phase was re-extracted thrice with $n$-hexane. All the quantities of $n$-hexane fraction were combined and dried in a rotary evaporator. The $n$-hexane extract was completely dried in a desiccator at about $40^{\circ} \mathrm{C}$ and kept in glass vials until used. The same method of fractionation was also applied to other solvents (ethyl acetate and $n$-butanol). The water phase at the end of the fractionation method was dried via rotary evaporator and desiccator and used as water fraction (Bakht et al., 2011c).

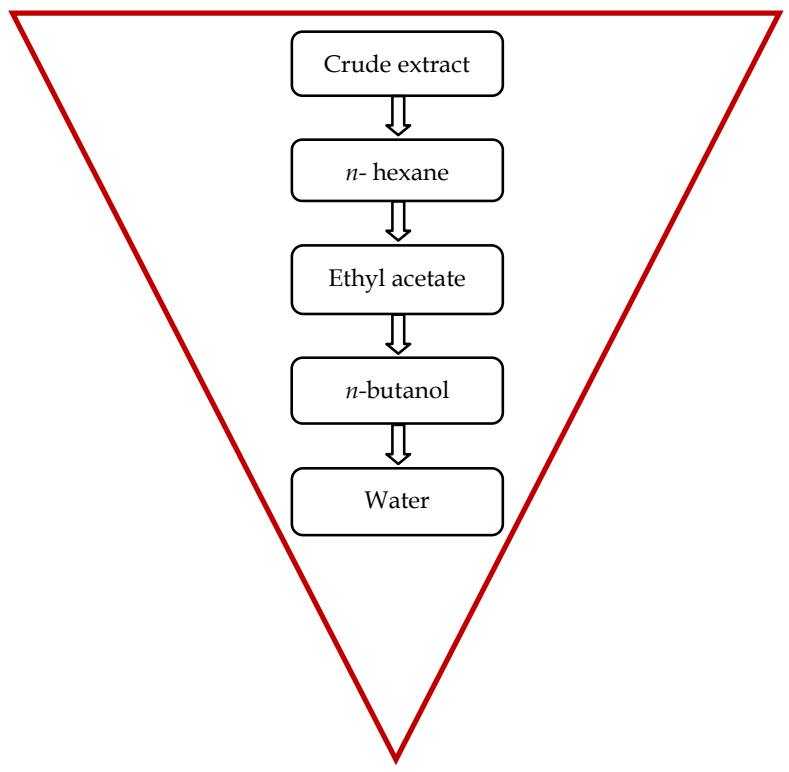

Figure 1: Flow chart of solvents arranged on ascending order of polarity used during experiment

\section{Antifungal activity and anti-oxidant bioassay}

The antifungal evaluation was performed according to the standard procedure (Khan et al., 2016). Fungal species used in this study were Candida albicans, Trichoderma reesei, Acremonium alternatum, Penicillium digitatum, Rhizopus Oryzae and Aspergillus flavus. These were obtained from the Department of Plant Pathology, The University of Agriculture Peshawar. Fungal strains were cultured on the potato dextrose agar media and standardized on potato dextrose broth. The standardized protocol, elaborated elsewhere, was used for the preparation of both media (Khan et al., 2016).

For the measuring of DPPH radical scavenging activity of the extracts, the standard procedure of anti-oxidant activity was recommended (Mensor et al. 2001). The details methodology for the assay can be found in our previous publication (Khan et al., 2016)

\section{HPLC assay of fractions}

Each fraction was run on HPLC for the quantification of gallic acid, equipped with water diode detector, 
(Shimadzu SPD-M20A), dualistic pump and diamonsil column C18 (diameter $4.6 \mathrm{~mm}$; length $250 \mathrm{~mm}$; particle size $2.5 \mu \mathrm{M}$ ). Standard methodology of HPLC assay was used in this study (Khan and Bakht, 2016). Gallic acid peaks were found in the different extracts with $\mathrm{Rt}=9.5$ $\pm 0.11 \mathrm{~min}$. These peaks were also confirmed by observing their UV spectra with standard (gallic acid). The concentration of gallic acid in different fractions was measured by applying the equation:

$y=46599 x+62968 ; R^{2}=0.998$

$y$ represents the area of peaks and $x$ show the concentration of gallic acid

\section{Statistical analysis}

Data of triplicate obtained during experiments were calculated and stated as mean \pm standard deviation using Microsoft Excel 2010.

\section{Results}

\section{Antifungal activity by well diffusion assay}

The antifungal potential of the tested extracts of leaf against Rhizopus oryzae is presented in Figure 2A. Only crude methanol extract possessed inhibitory activity against $R$. oryzae at different concentrations among the tested samples. The methanol extracts measuring 96, 93 and $86 \%$ inhibition at 400, 200 and 100 ppm concentra- tion respectively. The different solvents extracted samples of leaves were active against A. flavus except for water extract (Figure 2B). Crude methanol extract possessed maximum antifungal potency $(95 \% \quad \mathrm{ZI})$ shadowed by ethyl acetate $(64 \% \mathrm{ZI})$ and $n$-butanol fraction $(44 \%)$ at $400 \mathrm{ppm}$. These extracts also inhibited the growth of fungus at 200 ppm concentration (methanol extract 47\% ZI; ethyl acetate extracted fraction $45 \% \mathrm{ZI}$; $n$-butanol $41 \% \mathrm{ZI})$. On the other hand, the $n$-hexane extracted sample was active at $200 \mathrm{ppm}$ concentration $(34 \% \mathrm{ZI})$. The data further stated that ethyl acetate, $n$-butanol and $n$-hexane also possess antifungal potency at 100 ppm concentration, and however, the crude methanol extract did not reduce the growth of the tested fungus at the same concentration. Furthermore, crude methanol extract showed inhibitory activity against Pencillium digitatum (58\% ZI at 400 ppm concentration, $50.6 \% \mathrm{ZI}$ at $200 \mathrm{ppm}$ and $43 \% \mathrm{ZI}$ at 100 ppm). The other extracts of the leaves did not possess inhibitory activity against the same fungus. Trichoderma, and Acremonium strains were resistant to the leaf extracts. Similarly, the different solvent extracted samples of calyx, fruit and stem did not inhibit the growth of the tested fungus at all concentration.

\section{DPPH radical scavenging activity of extracts}

The radical scavenging activity of the different extracts from the stem is presented in Figure 3A. Methanol extracted fraction and water extracted fraction showed

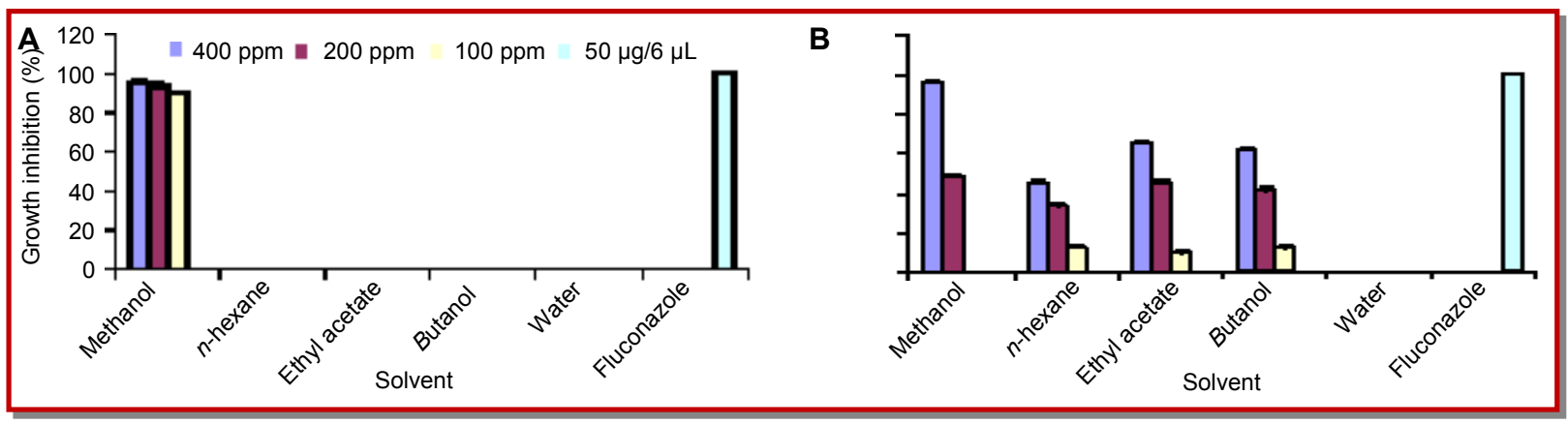

Figure 2: Antifungal potential of different solvent extracted samples of leaf against R. oryzae (A) and A. flavus (B)

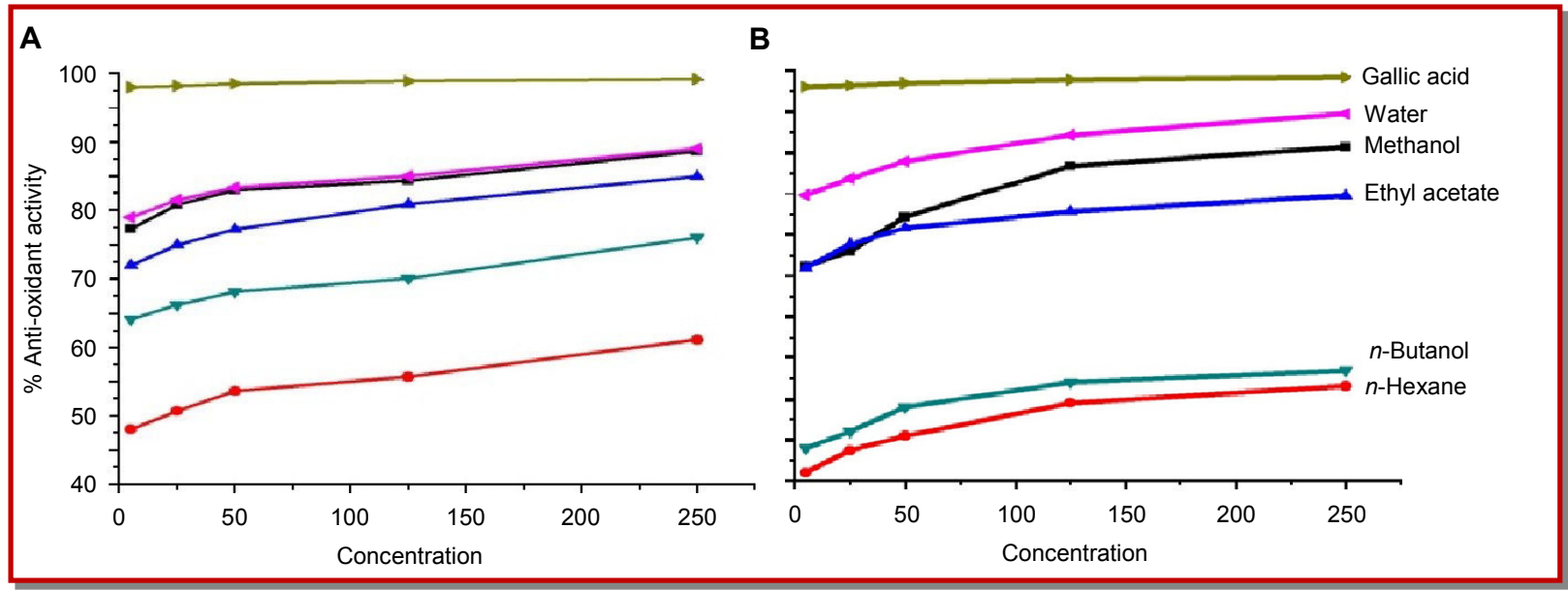

Figure 3: Anti-oxidant activity of the different extracts of the stem (A) and calyx (B) 


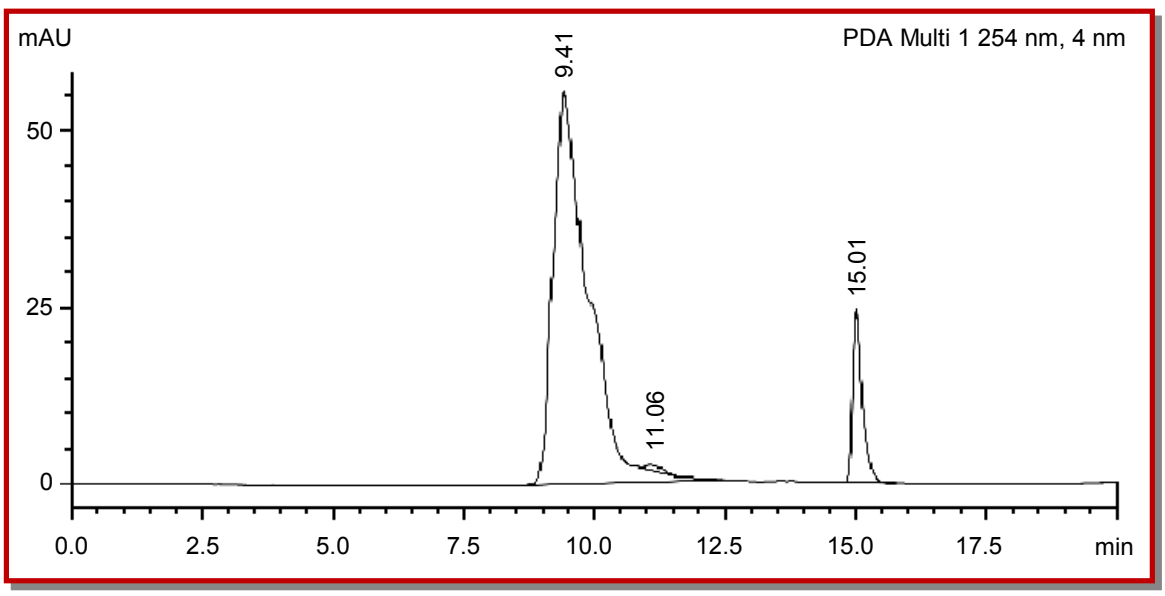

Figure 4: Chromatogram of ethyl acetate fraction of stem presenting gallic acid peak

the highest radical scavenging activity at $250 \mu \mathrm{g} / \mathrm{mL}$. The extracts according to the decreasing order of radical scavenging activity were methanol, water, ethyl acetate, $n$-butanol and $n$-hexane at the different concentrations. All these extracts possessed anti-oxidant potency at 5 $\mu \mathrm{g} / \mathrm{mL}$ concentration $(78.2 \%$ by water, $79 \%$ by methanol, $72 \%$ by ethyl acetate, $65 \%$ by $n$-butanol and $48 \%$ by $n$-hexane fraction). The different extracts of the leaves showed anti-radical properties, to varying degree at different concentrations. The crude methanol extract possessed strong anti-radical activity (94\%) shadowed by water extracted fraction (91\%) at $250 \mu \mathrm{g} / \mathrm{mL}$ concentration. The other extracts were also active at concentration of $250 \mu \mathrm{g} / \mathrm{mL}$ (i.e. $71 \%$ ethyl acetate, $69 \%$ $n$-butanol and $86 \% n$-hexane). However, at minimum concentration level $(5 \mu \mathrm{g} / \mathrm{mL})$, the descending order of antiradical activity of extracts was methanol (82\%), water fraction $(80 \%), n$-hexane extracted fractions (76\%), ethyl acetate (59\%) and $n$-butanol (58.3\%).

The tested extracts of calyx showed radical scavenging activity (Figure 3B). Among the tested samples, the water extract exhibited strong anti-oxidant activity (93\% at $250 \mu \mathrm{g} / \mathrm{mL}$ followed by methanol extract $(92 \%$ at $250 \mu \mathrm{g} / \mathrm{mL}$ ). Other extracts of calyx in order of decreasing potency were ethyl acetate, $n$-butanol and hexane extract fraction. Furthermore, all these extracts possessed antiradical property at minimum concentration of $5 \mu \mathrm{g} / \mathrm{mL}$ (i.e. water $85 \%$, ethyl acetate $76 \%$, methanol $71.3 \%, n$-butanol $54.3 \%$ and $n$-hexane $51.2 \%$ ).

Variation in radical scavenging activity was also found in different extracts of fruit. Water extracted fraction and methanol extract showed strong and same radical scavenging activity $(88 \%$ at $250 \mu \mathrm{g} / \mathrm{mL})$ shadowed by ethyl acetate extracted fraction $(79 \%$ at $250 \mu \mathrm{g} / \mathrm{mL})$. The descending order of antiradical activity of the other extracts were $n$-hexane (71\%) ethyl acetate extract $(81 \%)$ and $n$-butanol $(71 \%)$ at concentration of $250 \mu \mathrm{g} / \mathrm{mL}$. Only crude methanol extract (82\%) and ethyl acetate fraction $(72 \%)$ exhibited antiradical property at a concen -tration of $5 \mu \mathrm{g} / \mathrm{mL}$.

\section{HPLC assay}

In vitro evaluation of plant extracts through HPLC revealed the presence of high gallic acid content $(95 \pm$ $1.1 \mathrm{mg}$ GAE/g) in ethyl acetate dry extract of stem among all the tested samples (Figure 4). It is almost thrice of the concentration of gallic acid found in ethyl acetate extracted sample of the fruit $(34.0 \pm 0.9 \mathrm{mg}$ GAE/g). The minimum concentration of $0.04 \mathrm{mg}$ of gallic acid/g of dry extract was observed in $n$-butanol fraction of the calyx.

\section{Discussion}

In the current study, the inhibitory potential of extracts was evaluated against five fungal strains. Among the tested fungal strains, only three (R. oryzae, A. flavus and $P$. digitatum) were found to be susceptible to few extracts. Here, the potency of different extracts was compared with pure drug, which is still reasonable. There is a possibility that active ingredient isolated from the extracts might be effective as the standard drug or even more effective. The result of the current study revealed that only leaf part of the plant showed antifungal activity at different concentrations. The crude extract of leaf inhibited the growth of $R$. oryzae and $P$. digitatum at both minimum and maximum concentra-tion. Other extracts did not show inhibition of these fungal species. The existence of antifungal potential only in crude leaf extract may be due to the synergistic influence of various bioactive compounds in the same extract. The different extracts of leaf except water fraction were also effective against A. flavus at different concentrations. The growth of the fungus was highly inhibited by crude methanol extract shadowed by ethyl acetate and $n$-butanol fractions. Similar results have also been stated in previous studies like Johnson et al. (2008), Shariff et al. (2006) and Fridous et al. (1990).

The different extracts of various parts of the plant 
(stem, leaf, fruit and calyx) were evaluated for antioxidant activity. Analysis of our results clearly stated that leaf extracts possessed strong radical scavenging activity shadowed by extracts from stem, fruit and calyx. This difference in the anti-oxidant activity is due to the irregular distribution and localization of active compounds among the different parts of the plant. Besides this, the extracting solvent also affects the antiradical scavenging activity of the extract. In the previous studies the different solvents like methanol, acetone, ethyl acetate and propanol have been used for the recovery of anti-oxidant compounds (Alothman et al., 2009; Mahattanatawee et al., 2006). The selection of the suitable solvents for the optimum anti radical property of the extract is one of the challenging tasks due to the difference in solubility of anti-oxidant compounds in various solvents. Thus, preliminary screening is an essential to select the best solvent that finalizes the optimum antiradical activity of extract. The current study also pinpointed the suitable solvent for the optimum radical scavenging activity of the different parts of the plant. In the current study, five different solvents (methanol, $n$-hexane, ethyl acetate, $n$-butanol and water) were used for evaluating the antiradical property of different parts of the plant. Different extracts of leaf showed varying degree of radical scavenging activity. The methanol extract of the leaf, stem and fruit possessed strong radical scavenging activity as compared to other extracts, and increased with increasing concentration of extract. From these findings, it can be inferred that methanol could be the best solvent for the recovery of anti-oxidant compounds. For the calyx, the methanol and water extract showed approximately the same activity. Similar results have been reported in previous studies (Singh and Prakash, 2014; Bushra et al., 2009; Molyneux and Songklana-karin, 2004).

Studies of the gallic acid content through HPLC assay revealed the presence of high concentration of gallic acid in ethyl acetate extracts among the tested samples. The finding of high concentration of gallic acid in ethyl acetate solvent from the different parts of the plant showed good agreement with the results of Janovik et al. (2011), Boligon et al. (2009) and Schubert et al. (2007). Our finding showed no correlation between the gallic acid content and anti-oxidant capacity of the different parts of the plant. This can be explained by different features, including the presence of various bioactive compounds, their synergistic effect, structure feature of phenolic group and change produced by glycosylation (Jayaprakasha and Patil, 2007; Cho et al., 2003; Yu et al., 2002; Kahkonen et al., 1999).

\section{Conclusion}

Ethyl acetate was the best choice among the different solvents for the recovery of gallic acid from $P$. philadelphica.

\section{Acknowledgement}

The authors highly appreciated and acknowledged the Higher Education Commission (HEC) Pakistan for the financial support of research.

\section{Conflict of Interest}

Authors are unanimous in submitting the research paper to journal and there is no conflict of interest.

\section{References}

Alothman M, Bhat R, Karim AA. Anti-oxidant capacity and phenolic content of selected tropical fruits from Malaysia, extracted with different solvents. Food Chem. 2009; 115: 78588.

Arabshahi DS, Urooj A. Anti-oxidant properties of various solvent extracts of mulberry (Morus indica L.) leaves. Food Chem. 2007; 102: 1233-40.

Bakht J, Ali H, Khan MA, Khan A, Saeed M, Shafi M, Islam A, Tayyab M. Anti microbial activities of different solvents extracted samples of Linum usitatissimum by disc diffusion. Afr J Biotechnol. 2011c; 10: 19825-35.

Bakht J, Tayyab M, Ali H, Islam A, Shafi M. Effect of different solvent extracted samples of Allium sativum on bacteria and fungi. Afr J Biotechnol. 2011a; 10: 5910-15.

Bakht, J, Islam A, Shafi M . Antimicrobial potential of Eclipta alba by well diffusion method. Pakistan J Bot. 2011d; 43: 16166.

Behl C. Oxidative stress in Alzheimer's disease: Implications for prevention and therapy. Subcell Biochem. 2005; 38: 65-78.

Boligon AA, Pereira RP, Feltrin AC, Machado MM, Janovik V, Rocha JBT, Athayde ML. Anti-oxidant activities of flavonol derivates from the leaves and stem bark of Scutia buxifolia Reiss. Bioresour Technol. 2009; 100: 6592-98.

Bushra S, Anwar F, Ashraf M. Effect of extraction solvent/ technique on the anti-oxidant activity of selected medicinal plant extract. Molecules 2009; 14: 2167-80.

Cho EJ, Yokozava T, Rhyu DY, Kim SC, Shibahara N, Park JC. Study on the inhibitory effects of Korean medicinal plants and their main compounds on the DPPH radical. Phytomedicine 2003; 10: 544-51.

Desjardins AE, Manandhar G, Plattner RD, Maragos CM, Shrestha K, McCormick SP. Occurrence of Fusarium species and mycotoxins in Nepalese Maize and Wheat and the effect traditional processing method on mycotoxin levels. J Agric Food Chem. 2000; 48: 1377-83.

Devi KT, Mayo MA, Reddy G, Emmanuel KE, Larondelle Y, Reddy DVR. Occurrence of ochratoxin A in black pepper, coriander, ginger and turmeric in India. Food Addit Contam. 2001; 18: 830-35.

Dukic, NM, Bozin B, Sokovic M, Simin N. Antimicrobial and 
anti-oxidant activity of Melissa officinalis L. (Lamiaceae) essential oil. J Agric Food Chem. 2004; 52: 2485-89.

Fridous AJ, Islam SNLM, Faruque ABM. Antimicrobial activity of the leaves of Adhatoda vasica, Clatropis gigantean, Nerium odorum and Ocimum sanctum. Bangladesh J Bot. 1990; 19: 22729.

Galvano F, Piva A, Ritieni A, Galvano G. Dietary strategies to counteract the effect of mycotoxins: A review. J Food Protect. 2001; 64: 120-31.

Granger KL, Gallagher RS, Fuerst EP, Alldredge JR. Comparison of seed phenolic extraction and assay methods. Methods Ecol. Evol. 2011; 2: 691-98.

Gulcin I, Oktay M, Kirecci E, Kufrevioglu I. Screening of antioxidant and antimicrobial activities of anise (Pimpinella anisum L.) seed extracts. Food Chem. 2003; 83: 371-72.

Janovik V, Boligon AA, Bandeira RV, Athayde ML. HPLC/ DAD analysis, determination of total phenolic and flavonoid contents and anti-oxidant activity from the leaves of Cariniana domestica (Mart) Miers. Res J Phytochem. 2011; 5: 209-15.

Jayaprakasha GK, Patil BS. In vitro evaluation of the antioxidant activities in fruit extracts from citron and blood orange. Food Chem. 2007; 101: 410-18.

Johnson M, Maridass M, Irudayaraj V. Preliminary phytochemical and antibacterial studies on passiflora edulis. Ethnobot Leaflets. 2008; 12: 425-32.

Kahkonen MP, Hopia AI, Vuorela HJ, Rauha, JP, Pihlaja K, Kujala TS, Heinonen M. Anti-oxidant activity of plant extracts containing phenolic compounds. J Agric Food Chem. 1999; 47: 3954-62.

Khan BM, Bakht J. Antifungal, antiyeast, anti-oxidant and HPLC analysis of different solvent extracted samples from Calamus aromaticus leaves. Bangladesh J Pharmacol. 2016; 11: 91-100.

Khan W, Bakht J, Shafi M. Antimicrobial potentials of different solvent extracted samples from Physalis ixocarpa. Pakistan J Pharm Sci. 2016; 29: 467-75.
Mahattanatawee K, Manthey JA, Luzio G, Talcott ST, Goodner $\mathrm{K}$, Baldwin EA. Total anti-oxidant activity and fiber content of selected Florida-grown tropical fruits. J Agric Food Chem. 2006; 54: 7355-63.

Majumder UK, Gupta M, Mukhopadhyay DK. Effect of mycotoxins isolated from Penicillium nigricans on glucose-6phosphate dehydrogenase. Indian J Exp Biol. 1997; 35: 1233 36.

Marin S, Homedes V, Sanchis V, Ramos AJ, Magan N. Impact of Fusarium moniliforme and F. proliferatum colonisation of maize on calorific losses and fumonisin production under different environmental conditions. J Stored Prod Res. 1999; 35: $15-26$.

Mensor LI, Menezes FS, Leitao GG, Reis AS, Dos Santos T, Coube CS, Leitao CG. Screening of Brazillian plant extracts for anti-oxidant activity by the use of DPPH free radical method. Phytotherapy Res. 2001; 15: 127-30.

Molyneux P, Songklanakarin. The use of the stable free radical diphenylpicrylhydrazyl (DPPH) for estimating anti-oxidant activity. J Jpn Soc Food Sci Technol. 2004; 26: 211-19.

Schubert A, Pereira DF, Zanin FF, Alves SH, Beck Athayde ML. Comparison of anti-oxidant activities and total polyphenolic and methylxanthine contents between the unripe fruit and leaves of Ilex paraguariensis A. St Hil Pharmazie. 2007; 62: $876-80$.

Shariff N, Sudharshana MS, Umesha S, Hariprasad P. Antimicrobial activity of Rauvolfia tetraphylla and Physalis minima leaf and callus extracts. Afr J Biotechnol. 2006; 5: 94650.

Singh S, Parkash P. Evaluation of anti-oxidant activity of Physalis minima. Chem Sci Trans. 2014; 3: 1179-85.

Ullah R, Bakht J, Shafi M. Antimicrobial and anti-oxidant potential of Periploca hydaspidis. Bangladesh J Pharmacol. 2015; 10: 645-51.

Verma J, Dubey NK. Prospective of botanical and microbial products as pesticides of tomorrow. Curr Sci. 1999; 76: 17279. 